\title{
СОВРЕМЕННЫЕ ВЫЗОВЫ БАНКОВСКОЙ ОТРАСЛИ В СТРОИТЕЛЬСТВЕ
}

\author{
(c) 2020 Цапикова Елизавета Алексеевна \\ студент специалитета кафедры «Строительство уникальных зданий и сооружений» \\ Сибирский федеральный университет, Россия, Красноярск \\ E-mail: capikova19@gmail.com \\ (c) 2020 Катцина Эмма Вадимовна \\ студент специалитета кафедры «Строительство уникальных зданий и сооружений» \\ Сибирский федеральный университет, Россия, Красноярск \\ E-mail: kattsinaemma@mail.ru
}

(c) 2020 Лопатина Полина Максимовна

студент специалитета кафедры «Строительство уникальных зданий и сооружений»

Сибирский федеральный университет, Россия, Красноярск

E-mail: polinalopatina4@mail.ru

(c) 2020 Полуштайцева Валерия Владимировна

студент кафедры инженерных систем зданий и сооружений

Сибирский федеральный университет, Россия, Красноярск

E-mail: polushtaytseva@bk.ru

\section{(c) 2020 Рослякова Мария Александровна}

студент специалитета кафедры «Строительство уникальных зданий и сооружений»

Сибирский федеральный университет, Россия, Красноярск

E-mail: roslyakovamary@mail.ru

Строительная отрасль - важная составляющая экономики любого государства. Ввиду этого, вопрос развития данной отрасли заслуживает особого внимания. Финансирование строительных проектов зачастую сопровождается рядом проблем, особенно в странах, экономика которых не является стабильной. На сегодняшний день одной из главных задач стратегического управления хозяйственной системой страны является поиск источников финансирования для основного капитала, потому как собственные средства субъектов часто бывают ограничены в размере. Вследствие этого происходит повышение популярности банковского кредитования в качестве источника инвестиций в строительной сфере.

В статье представлен анализ современных вызовов банковской отрасли относительно строительства, а также рассмотрены варианты решения основных проблем.

Ключевые слова: строительство, проектное финансирование, банковская отрасль, экономика, вызовы банковской отрасли, ВІМ-технологии.

Одной из основополагающих отраслей любой страны, в том числе и России, является строительная сфера, которая обеспечивает формирование экономики страны. На строительство, как и на другие отрасли, влияют экономические и политические тенденции.

Такие факторы как стоимость нефти, валютный курс, уровень инфляции, потребность в недвижимости, ключевая ставка рефинансирования, доступность кредитных средств, а так же возможность использования государственных источников финансирования в России, имеют основополагающий характер для начала стро- ительства. Помимо этого, на экономическое развитие нашей страны оказывает негативное воздействие внешнеполитическая ситуация, а именно санкции, направленные против России.

В связи с ограниченностью финансовых ресурсов строительных компаний, одной из основных проблем становится обеспечение достаточности денежных средств для реализации проектов.

При уменьшении капитальных вложений инвесторов основным источником ресурсов для строительства являются собственные средства строительной организации, банковское 
или бюджетное финансирование. Средства из бюджетного фонда ориентированы в основном на возведение объектов для жилищного или социального назначения. Главный посыл всех программ финансирования из бюджетных средств - это обеспечение благоприятных условий и доступных финансовых продуктов для граждан страны с целью покупки жилья за счет кредитных средств. При получении ипотечного кредитования, существующие задачи решаются с помощью большего вовлечения банков в систему финансирования жилищного строительства, путем предоставления последним дополнительных государственных льгот и гарантий.

Значимым сектором отрасли строительства является жилищное строительство, которое значительно превышает по статистике ввода в эксплуатацию другие отрасли. Жилищный фонд зданий является основополагающим фактором развития и размещения производственных сил [1].

Роль банковской отрасли в строительстве значительно возросла в связи с изменениями федерального закона 214 «О долевом участии в строительстве», который предполагает переход на новую схему взаимодействия участников правоотношений: застройщика и дольщика. До принятия данных поправок участники долевого строительства в период возведения дома передавали свои средства напрямую застройщику, который распоряжался ими по своему усмотрению, что в конечном счете не давало никаких гарантий дольщику. Это привело к увеличению случаев обмана со стороны застройщика и люди оставались без денег и без жилья [2].

Именно поэтому с первого июля 2019 года все застройщики начали переходить на обязательное проектное финансирование. В результате чего средства на строительство они будут получать от кредитного учреждения. Рассмотрим особенности проектного финансирования:

1. Средства на строительство девелопер может получить от инвестора или использовать собственные.

2. Перед тем как дать кредит банк должен провести обязательную проверку компаниизастройщика, чтобы исключить ненадежных партнеров.

3. Банк будет контролировать проект, который проинвестировал для того, чтобы избежать нерационального расходования выделенных средств.
4. Под каждый строительный проект создается своя проектная компания.

5. Перед выделением средств проводится составление и согласование бизнес-плана, в ходе которого решаются такие организационные вопросы как договоры с поставщиками, подбор кадров и т.п.

Особенно важно упомянуть эскроу-счёт. Это счёт, на котором дольщики будут хранить свои деньги. Именно на этот счёт будут поступать средства для строительства. При этом у застройщика нет доступа к нему. Суть эксроу-счёта состоит в том, что застройщик не сможет получить деньги до тех пор, пока не передаст квартиру покупателю. Это позволяет избежать мошенничества и защитить средства при банкротстве.

В результате данной реформы были сформулированы вызовы банковской отрасли в сфере строительства, которые рассмотрены ниже:

1. Проблемы взаимоотношения застройщиков и банков

Необходимость защиты всех расходов по строительному проекту усложняет процесс реализации проекта для застройщика. Банк, как правило, отказывается финансировать непрофильные расходы (спонсорские, социальные и др.). Но без социальных проектов у застройщика появляются проблемы с властями, а интерес покупателей к такому проекту падает. Из-за этого застройщик вынужден выделять собственные деньги, которые вряд ли потом будут включены в счёт проекта [3].

Для таких спорных ситуаций нужно привлекать третью сторону, которой могут стать независимые эксперты, обладающие необходимыми компетенциями.

2. Недостаточное развитие проектного финансирования в России

По данным на январь 2020 года в 71 субъекте Российской Федерации возводилось 1100 объектов жилищного строительства с помощью проектного финансирования и счетов эскроу. Эти данные в более чем в пять раз превосходят число проектов по состоянию на 1 июля 2019 года (217 объектов в 50 регионах), когда строительство жилого фонда в рамках законодательства было переведено на новую систему финансирования. По данным на 3 февраля 2020 года с застройщиками заключено 826 кредитных договоров в рамках проектного финансирования на сумму 958 млрд. руб. Большая часть проектов (50,7\%) приходится на Москву, далее следует Москов- 
ская область (10,3\%) и Санкт-Петербург (6,5\%). На остальные 75 субъектов приходятся $17,7 \%$ от всего объема проектного финансирования. В то время, у 19 регионов данный показатель равен нулю [4].

Замечено, что на данный момент объемы проектного финансирования немного замедлились, это вызвано влиянием внешних факторов и имеет временный характер.

Однако, не смотря на положительную динамику, по данным Банка России только 65\% поданных заявок на проектное финансирование ободряют по причине непредставления застройщиком надлежащего пакета документов.

Больше третей части отказов связно с несоответствием проекта кредитной политике банка. Организация, выдающая кредит обращает внимание на число проектов, построенных застройщиков, на наличие проблем в процессе строительства и на претензии от заказчика и подрядчика, а также были ли у него судебные разбирательства.

На данный момент механизм проектного финансирования в Российской Федерации требует доработки в рамках законодательства для упорядочения взаимоотношений между банком и застройщиком. Основными катализаторами роста проектного финансирования в России может быть обеспечение макроэкономической стабильности и совершенствование методики принятия рациональных и эффективных управленческих решений на всех стадиях реализации проекта.

В современных реалиях проектное финансирование имеет слабую законодательную основу и правовую защищённость. Из-за этого застройщики могут использовать хитрости, для того чтобы обойти исполнение всех обязательств.
Переход на проектное финансирование жилищного строительства имеет ряд достоинств и недостатков. Но главная задача реформы - peшить проблему обманутых дольщиков.

К достоинствам реформы можно отнести тот факт, что экскроу-счета защищают покупателей новостроек. Также им гарантируются страховые выплаты в размере до десяти миллионов рублей. Реформа позволяет отсеять ненадежные компании, делая рынок прозрачным и стабильным. Несомненным плюсом является то, что банки могут контролировать расходы и не допускать ненужных вложений. Стоит отметить, что в Европе эта схема используется достаточно давно и доказала своё качество и эффективность.

Благодаря этой реформе роль банков в приобретении жилья увеличивается. Они дают застройщикам дополнительные гарантии и берут на себя часть рисков. Благодаря строгим контролем над качеством проектов повысится конкурентоспособность продуктов, что повлияет на развитие данной отрасли.

На стоимость фондирования повлияет снижение рисков в этой сфере. Внешние обстоятельства не смогут сильно повлиять на проекты, так как банк сможет защитить застройщика.

Таким образом, благодаря отсеиванию непрофессиональных компаний, усилению конкуренции, а следовательно, повышению качества позволит сделать рынок надёжным, стабильным и успешным. А взаимодействие девелоперов с банками позволит избежать срывов сроков, неликвидность продукта и неэффективную реализацию проекта.

K недостаткам реформы можно отнести увеличение стоимости новостроек. Это может привести к уходу с рынка множества девелоперских

\begin{tabular}{llc}
\hline № & \multicolumn{1}{c}{ Регион } & \% проектного финансирования \\
\hline 1 & Москва & $51 \%$ \\
\hline 2 & Московская область & $10 \%$ \\
\hline 3 & Санкт-Петербург & $7 \%$ \\
\hline 4 & Республика Татарстан (Татарстан) & $3 \%$ \\
\hline 5 & Ленинградская область & $2 \%$ \\
\hline 6 & Свердловская область & $2 \%$ \\
\hline 7 & Краснодарский край & $2 \%$ \\
\hline 8 & Ростовская область & $2 \%$ \\
\hline 9 & Тюменская область & $2 \%$ \\
\hline 10 & Новосибирская область & $2 \%$ \\
\hline
\end{tabular}

Рисунок 1. 10 крупнейших регионов РФ по объему проектного финансирования 
компаний. Из-за этого возможна угроза монополизации рынка крупными застройщиками. Также банки скорее всего не смогут профинансировать все стройки, так как им не будет хватать средств для такого большого масштаба. На начальном этапе реализации реформы не исключены ошибки во взаимодействии банков и застройщиков, что может привести к банкротству некоторых компаний.

Также стоит отметить, что жилищное строительство попадает в зависимость от Центрального Банка и правительства. Ведь банки станутся единственной возможностью для получения кредита. Уполномоченных банков не так много по сравнению с девелоперскими компаниями. Крах банка может привести к нарушению графика строительства или его полной остановки. При этом государство не гарантирует застройщику, что банк, в котором он взял кредит не обанкротится. Таким образом, такая зависимость банка от застройщика делает создают множество рисков для строительства.

Ещё одной проблемой является тот факт, что застройщики маленьких городов рискуют остаться без финансовой поддержки, а именно в провинциальных городах проблема обновления жилья стоит особенно остро. А снижение конкуренции в одном городе может привести к большому количеству однотипных строительных проектов [5].

3. Сложность контроля над процессом строительства объектов

В рамках проектного финансирования банку необходимо контролировать использование денег застройщиком. Учитывая то, что строительство - это сложный и долговременный процесс, для осуществления контроля банку необходимо иметь штат сотрудников, специализирующихся на экспертизе строительства, которые будут проводить мониторинг за всеми процессами стройки, что влечет за собой немалые расходы.

Данная проблема может быть решена с помощью комплексного подхода, который затрагивает строительную и банковскую отрасли. Этот подход заключается в использовании BIM-технологии (Building Information Modeling) в период разработки строительного проекта, которая позволяет создать не только информационную модель всего здания, но и базу данных. Благодаря BIM изменение строительных процессов можно контролировать в режиме реального времени. Этот подход упрощает работу строителей и помогает банкам эффективнее контролировать работу застройщиков.

BIM-технологии появились еще в 80-х годах прошедшего века и на сегодняшний день являются одной из самых актуальных тем в строительной сфере. В данной технологии заинтересованы инвестора и девелоперы в качестве инструмента, который дает возможность уменьшить затраты времени и финансов благодаря автоматизации «ручных» процессов в проектировании строительных объектов. ВІМ позволяет быстро вносить коррективы в проект без потери качества.

В процессе внедрения ВIM на отечественный строительный рынок заинтересовано государство, так как эта технология позволяет получать актуальную информацию об объекте в цифровом формате, благодаря этому упрощаются и ускоряются процессы согласования документации и формирование единой базы данных.

Говоря о международном опыте внедрения BIM-технологий можно сказать, что данный процесс «подкреплен» не только стремлением девелоперов к цифровизации, но так же считается необходимым для реализации проектов с участием государства и иных коммерческих организаций.

Великобритания - одна из стран-лидеров по внедрению ВIM. В 2011 году правительство Великобритании сделало обязательным условием создание трехмерной модели объекта строительства. На момент января 2019 года по данным «National BIM Report 2019», использование BIM увеличилось с 10\% до 70\% (за период с 2011 по 2019 гг).

Задумка использовать ВІМ-технологию в США появилась в 70-е годы, однако внедрение началось в 90-х годах. Позже в 2003 году была сформирована Национальная программа «3D-4D-BIM Program», в которой было оговорено обязательное применение BIM для проектирования общественных зданий, а с 2007 года для разработки кадастровых и геопространственных данных [6].

Проблемы, связанные с внедрением BIMтехнологии.

В случае отсутствия возможности использования традиционных методов ВIM применяется более масштабно и на высоком уровне. Это происходит из - за того, что строительство уникальных зданий и сооружений является сложным в техническом отношении процессом. 


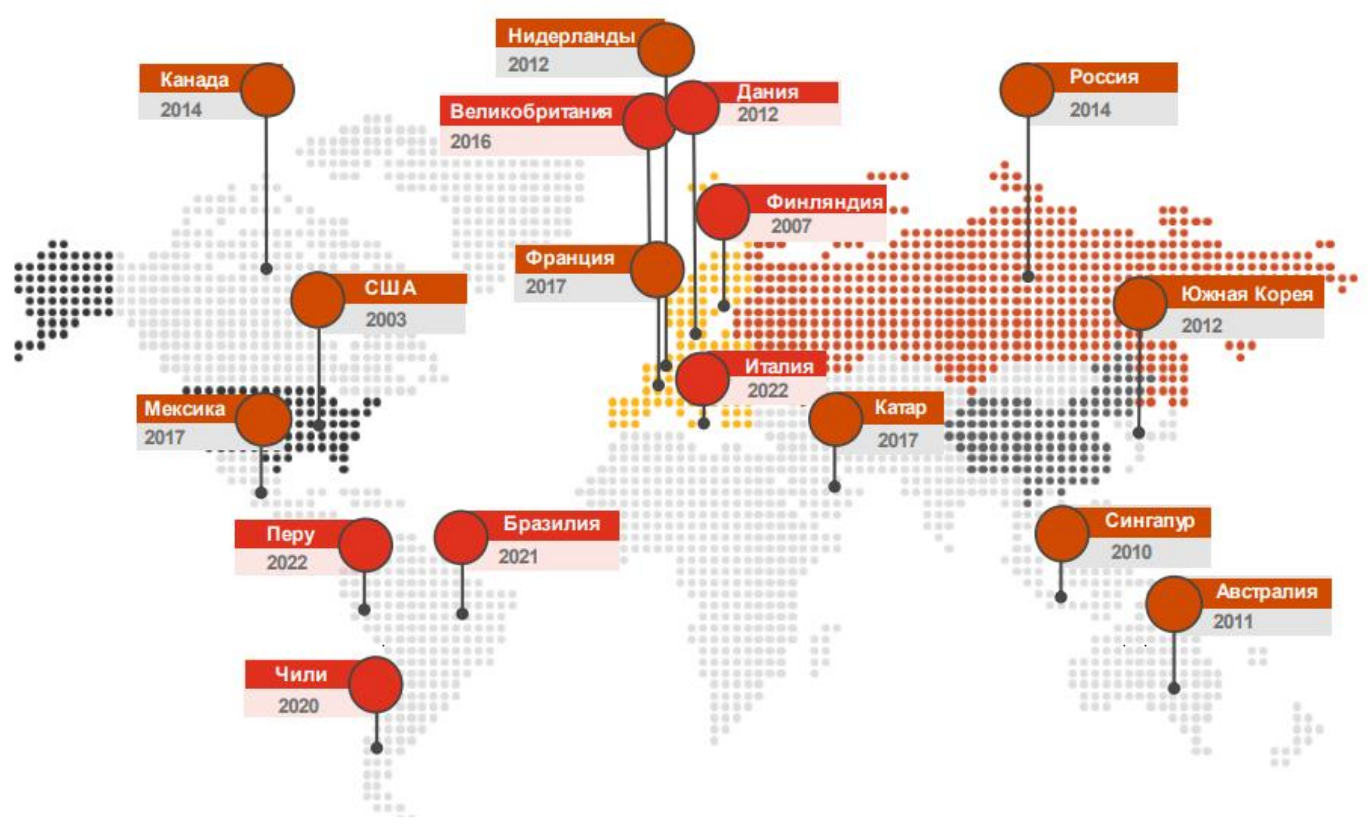

Рисунок 2. География внедрения BIM

Ниже представлены показатели, влияющие на процесс внедрения ВIM:

- Стоимость годовой версии на одного пользователя в год составляет от 65тыс. руб.;

- Стоимость базового курса обучения работы с программным обеспечением BIM моделирования составляет от 20 до 30 тыс. руб. на одного работника;

- Процесс внедрения ВIM в компанию составляет 6-12 месяцев;

Кроме этого российскому строительному рынку свойственны следующие барьеры:

- Недостаток понимания и трудности в подсчете экономической эффективности;

- Высокие первоначальные вложения капитала, недостаток квалифицированных специалистов;

- Высокая потребность в доработке нормативно-правовой базы;

- Недостаток четного представления о ВIM-технологии;

- Отсутствие технической обеспеченности участников строительного проекта;

- Потребность в масштабном измерении внутренних процессов.

Экономический эффект от внедрения ВІМ-технологии.

Не смотря на все достоинства и возможности, которые открываются используя ВIM-технологии, преобразования в организации создают естественный протест со стороны представи- телей отрасли, которые отрицают целесообразность применения новой технологии.

По данным членов строительного рынка, peзультат от внедрения ВIM - технологии имеет накопительный эффект благодаря уменьшению затрат на всех этапах строительства. Согласно отчету национального объединения изыскателей и проектировщиков «Оценка применения BIM-технологий в строительстве», за счет применения BIM решений возможно достигнуть следующих экономических эффектов:

- Увеличение до 25\% показателя чистого дохода;

- Рост до 15\% индекса рентабельности;

- Увеличение до 25\% показателя внутренней нормы доходности;

- Сокращение срока окупаемости до $17 \%$.

В целом прослеживается тенденция: при росте количества проектов растет и доля компаний, использующих ВІМ.

Также ВIM-технологии позволяют сократить сроки реализации проекта за счёт более качественного планирования графиков. При помощи этих технологий становится возможным точно посчитать объемы материалов, провести тендеры и осуществить закупку без потери времени и средств.

K другому преимуществу этих технологий можно отнести тот факт, что при соблюдении регламентов ВIM гарантирует более высокое качество проекта. Он не может заменить профес- 


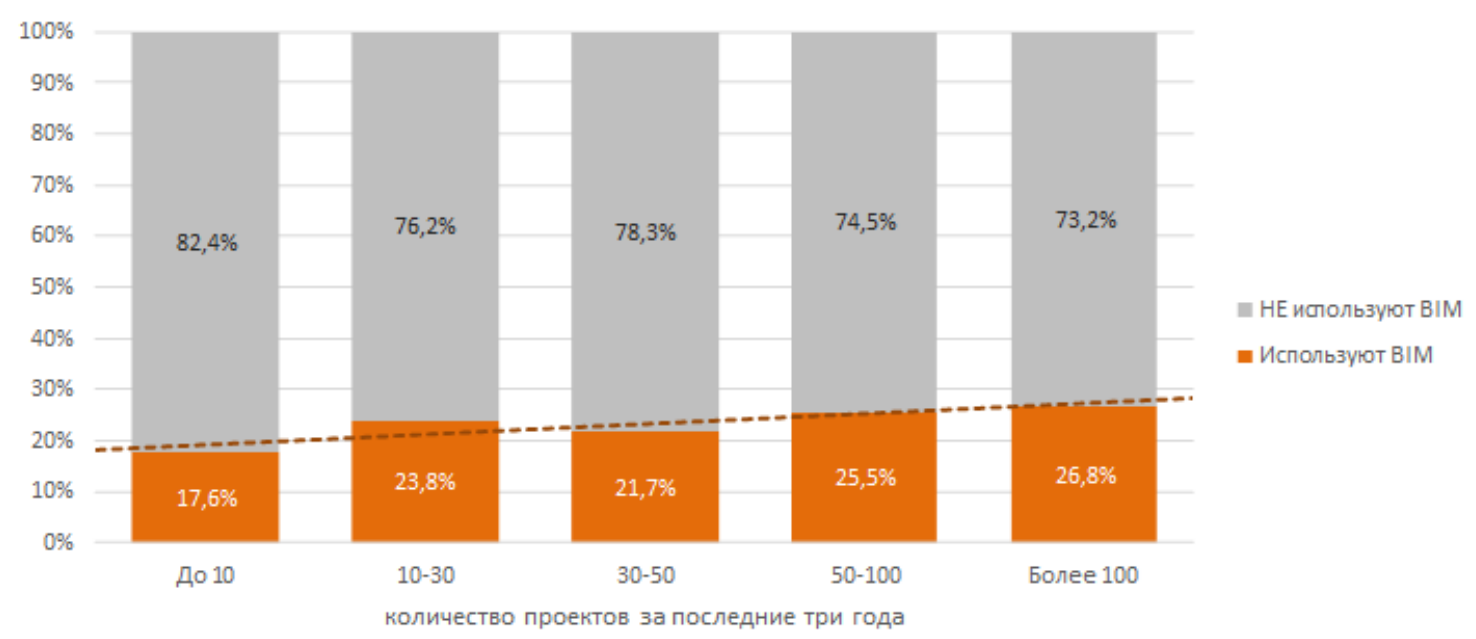

Рисунок 3. Доля использующих и не использующих ВIM в зависимости от количества проектов

сионализм проектировщика или планировщика, но координация моделей по дисциплинам в работе команды позволяет существенно увеличить качество результата.

K достоинствам ВIM-технологий можно отнести их стоимость. Исследование и анализ российского проектирования продемонстрировали, что затраты на строительство уменьшились до десяти процентов. Применение BIM не только во время проектирования, но и на этапе возведения объекта существенно увеличивает качество выполнения работ, а также позволяют избежать ошибок и сэкономить на строительстве [7].

Помимо этого, преимущество использования ВIM заключается в прозрачности. ВIM дает возможность проверить смету по модели, сравнить с аналогичными проектами и контролировать ход разработки и реализации проекта. Поэтому для государственного заказчика было бы чрезвычайно полезно заказывать в ВIM бюджетные проекты с точки зрения рационального использования бюджетных денег.

Основываясь на вышесказанном, можно сделать вывод, что использование BIM-технологии позволит сократить стоимость всего строительства, а также поможет организовать структуру контроля за этапами стройки. При проектировании с помощью ВIM-технологий проект моделируется из электронных версий объектов реального мира, каждый из которых имеет свои свойства, материал, тип и точную геометрию. Благодаря этому из сформированной модели генерируются чертежи, планы, фасады. При этом изменения в документацию вводятся автоматически, что исключает ошибку при внесении правок. Таким образом документация получается согласованной и свободной от ошибок.

Подводя итоги, можно сделать вывод о том, что вызовы банковской отрасли относительно строительства очень актуальны в наше время. Решение насущных проблем требует проведение реформ, которые направлены на совершенствование нормативной базы для урегулирования отношений банковской и строительной отраслей, а так же внедрение новых технологий в процессы строительства, которые позволят сократить расходы не только застройщика, но и банка.

\section{Библиографический список}

1. Крысин А. В. Роль банков в финансировании жилищного строительства: проблемы и перспективы/ А. В. Крысин // Банковское дело. - 2011 - № 7. С. 58-61

2. О внесении изменений в Федеральный закон «Об участии в долевом строительстве многоквартирных домов и иных объектов недвижимости и о внесении изменений в некоторые законодательные акты Российской Федерации и отдельные законодательные акты Российской Федерации»: федеральный закон РФ от 27.06.2019 № 151-Ф3 // Российская газета.-2019. - 1 июля.

3. Проектное финансирование строительства жилья: плюсы и минусы реформы [Электронный ресурс] URL: https://realty.rbc.ru/news/5c63d9ac9a79473a78550fd9 (Дата обращения 26.07.2020) 
4. ЦБ: более половины проектного финансирования в стране и около трети счетов эскроу приходится на Москву и Подмосковье [Электронный ресурс] URL: https://erzrf.ru/news/tsb-boleye-poloviny-proyektnogofinansirovaniya-v-strane-i-okolo-treti-schetov-eskrou-prikhoditsya-na-moskvu-i-podmoskovye (Дата обращения 26.08.2020)

5. Факанова К. Банк как инструмент реализации инвестиционного проекта в строительстве/ К. Факанова// Риск: ресурсы, информация, снабжение, конкуренция. - 2014 - № 2. С. 279-282

6. PropТесh в России 2020. Обзор практики применения ВІМ-технологий и инновационных решений в области проектирования. [Электронный ресурс] URL: https://www.pwc.ru/ru/publications/proptech-russia-2020. html?from=bimlib.pro (Дата обращения 26.08.2020)

7. ВІМ-технологии позволяют сократить затраты на строительство до 10\% - эксперт [Электронный ресурс URL: https://stroi.mos.ru/news/bim-tiekhnologhii-pozvoliaiut-sokratit-zatraty-na-stroitiel-stvodo-10-ekspiert?from=cl (Дата обращения 26.07.2020) 